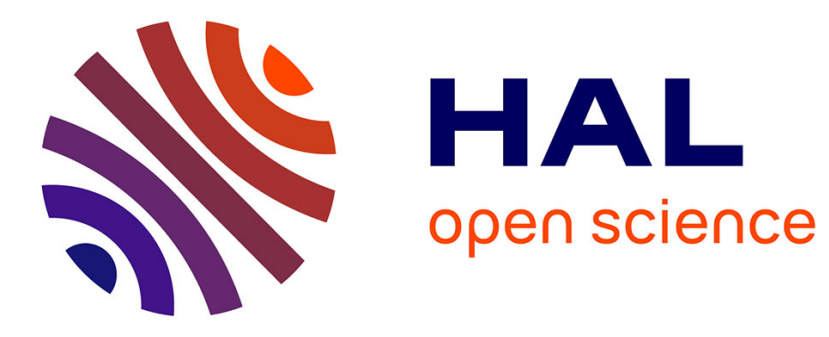

\title{
Agile solid state dye lasers
}

Michael Canva, Patrick Georges, Jean-François Perelgritz, Alain Brun, Frédéric Chaput, Jean-Pierre Boilot

\section{To cite this version:}

Michael Canva, Patrick Georges, Jean-François Perelgritz, Alain Brun, Frédéric Chaput, et al.. Agile solid state dye lasers. Journal de Physique IV Proceedings, 1994, 04 (C4), pp.C4-369-C4-372. 10.1051/jp4:1994488 . jpa-00252751

\section{HAL Id: jpa-00252751 https://hal.science/jpa-00252751}

Submitted on 1 Jan 1994

HAL is a multi-disciplinary open access archive for the deposit and dissemination of scientific research documents, whether they are published or not. The documents may come from teaching and research institutions in France or abroad, or from public or private research centers.
L'archive ouverte pluridisciplinaire HAL, est destinée au dépôt et à la diffusion de documents scientifiques de niveau recherche, publiés ou non, émanant des établissements d'enseignement et de recherche français ou étrangers, des laboratoires publics ou privés. 


\title{
Agile solid state dye lasers
}

\author{
M. CANVA, P. GEORGES, J.-F. PERELGRITZ, A. BRUN, F. CHAPUT* and J.-P. BOILOT* \\ Groupe d'Optique Non-Linéaire, Institut d'Optique Théorique et Appliquée, Unité Associée 14, Centre \\ National de la Recherche Scientifique, Bâtiment 503, BP. 147, 91403 Orsay cedex, France \\ ${ }^{*}$ Groupe de Chimie du Solide, Laboratoire de Physique de la Matière Condensée, Unité Associée 1254-D, \\ Centre National de la Recherche Scientifique, Ecole Polytechnique, 91128 Palaiseau cedex, France
}

\begin{abstract}
Different organic dye molecules were incorporated in solid gels by the sol gel process with a view to develop tunable solid state laser applications.

We studied the laser efficiency of these materials by using a nanosecond frequency doubled Nd:YAG as the pump laser. Slope efficiency up to $30 \%$ with $3 \mathrm{~mJ}$ output energy and half energy lifetime of 40,000 shots were thus obtained. This large lifetime was observed with the perylene red molecules despite of a lower slope efficiency (19\%).

Tunability over $50 \mathrm{~nm}$ was obtained with the perylene or pyrromethene dyes and $75 \mathrm{~nm}$ in the case of the xanthylium dye.
\end{abstract}

For the past decade, much research has been done in attempt to trap organic dye molecules, such as rhodamine $6 \mathrm{G}$, in solid matrix which could then be used as gain media for tunable pulsed lasers. To serve this purpose, the host matrix has to fulfill several requirements. It has to have a large transparent band and must not be diffusing. Its mechanical properties has to allow the possibility to achieve a good optical polishing. Its synthesis must be compatible with the introduction of the organic dye molecules as dopants; particular points are solubility which may limit the concentration of encaged molecules and heat treatment, occurring during the process, which could degrade the organic dye. The local environment, provided to the encaged dye molecules, must allow the latter to be strongly fluorescent and photostable, as already known in usual solvents. Finally, and last of these major points, the material must be stable with time, this requirement concerning both the matrix and the dye, and their interactions.

Many types of matrices have been tried, some with success. However we believe that the sol gel process could be a good solution to this problem. It allows to synthesize, by inorganic polymerization, at room temperature, a gel matrix from solution. The resulting xerogel may be at choice totally inorganic (ex: $\mathrm{SiO}_{2}$ gel) or hybrid inorganic/organic. In this last case, the organic part may be located on the pore surfaces, thus being in contact with a potential dopant. These unique features allow to answer point per point at the host matrix requirements. The inorganic part insures the rigidity of the network and may be dense enough to fulfill the mechanical properties to obtain the optical polishing and transparency required. It may also provide the thermal properties needed to achieve the stable operation of the solid state dye laser. The organic part may be chosen to provide a dopant environment favorable to the fluorescence emission of the trapped dye.

The matrix concerned in this communication is an hybrid organic/inorganic xerogel : organic vinyl $\left(-\mathrm{CH}=\mathrm{CH}_{2}\right)$ groups are attached on a silica network (approximate composition $\mathrm{SiO}_{1.5}\left(\mathrm{CH}=\mathrm{CH}_{2}\right)$ ). It was prepared by hydrolysis-condensation of the vinyltriethoxysilane, 
$\left(\mathrm{CH}=\mathrm{CH}_{2}\right)-\mathrm{Si}\left(-\mathrm{O}-\mathrm{C}_{2} \mathrm{H}_{5}\right)_{3}$, precursor under acid-catalysed conditions. The doping molecules were chosen for their superior properties compared to that of the classical rhodamine $6 \mathrm{G}$. We used perylenes and pyrromethenes dyes for their better thermal and photo-stability and the new 3,11-dimethoxy-5,6,8,9-tetrahydro dibenzo xanthylium tetrafluoroborate molecules recently developed [1] for its large fluorescence band. After gelation, the samples were left to dry about three weeks at $40^{\circ} \mathrm{C}$. The closed porosity doped xerogels obtained, about $4 \mathrm{~cm}$ of diameter and $5 \mathrm{~mm}$ of thickness, were then polished to achieve a $4 \mathrm{~nm}$ roughness.

To study the performances of the samples as gain media, they were placed in a $15 \mathrm{~cm}$ linear plano-concave cavity. The high reflection concave mirror had $2 \mathrm{~m}$ radius curvature. The transmission of the flat output coupler was $80 \%$. A dichroïc flat mirror folded the cavity allowing longitudinal pumping. The pump beam consisted of 8 nanosecond pulses issued from a frequency doubled Q-switched Nd:YAG laser. The energy used was up to $10 \mathrm{~mJ} / \mathrm{pulse}$. These pump pulses were focused into the sample with a spot diameter of $800 \mu \mathrm{m}$, at $3 \mathrm{~cm}$ from the output coupler. It should be noted that the experimental results depend strongly on the experimental set-up and conditions, especially pump energy fluence in the sample and repetition rate.

With this cavity set-up, the typical results obtained were as follows : thresholds about $200 \mu \mathrm{J}$ pump energy and slope efficiencies between 15 and $30 \%$ depending on the choice of the dye and its concentration. The best result was obtained with a pyrromethene 567 doped sample with a concentration of $5.5 \times 10^{-4} \mathrm{~mol} / 1$ in the initial sol : pulses of $3 \mathrm{~mJ}$ energy were issued from the cavity when pumping with $10 \mathrm{~mJ} /$ pulse $\left(2 \mathrm{~J} / \mathrm{cm}^{2}\right.$ fluence $)$ [Fig. 1], thus corresponding to a slope efficiency of about $30 \%$. For the other dyes the slope efficiencies were the following : $25 \%$ with a perylene orange doped xerogel $\left(c=10^{-4} \mathrm{~mol} .1^{-1}\right.$ in the sol), $19 \%$ with a perylene red doped xerogel $\left(c=4.410^{-4}\right.$ mol. $\left.1^{-1}\right), 14 \%$ with a 3,11 - dimethoxy $5,6,8,9$ - tetrahydro dibenzo xanthylium tetrafluoroborate doped xerogel $\left(\mathrm{c}=10^{-3} \mathrm{~mol} . \mathrm{1}^{-1}\right)$ and $15 \%$ with a rhodamine $6 \mathrm{G}$ doped xerogel $\left(c=10^{-4} \mathrm{~mol} . \mathrm{l}^{-1}\right)$. The pump energy threshold was in all cases around 100 to $200 \mu \mathrm{J}$ and no saturation of the output energy was observed in the $100 \mu \mathrm{J}-3 \mathrm{~mJ}$ range. This maximum pumping energy of $10 \mathrm{~mJ}$ focused on $800 \mu \mathrm{m}$ diameter, corresponding to a fluence of $2 \mathrm{~J} / \mathrm{cm}^{2}$, is about the limit for which the matrix is sometimes damaged. These efficiency data are given for a single shot utilization of the laser.

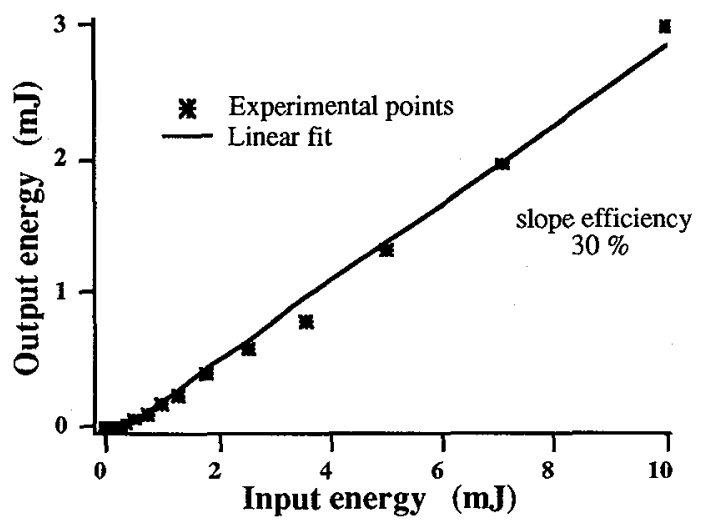

Figure 1; Efficiency of the laser cavity when using a pyrromethene 567 doped sample with a concentration of $5.5 \times 10^{-4}$ mollt in the initial sol.

The spatial profile of the output beam was recorded with a CCD camera and is given on figure 2 in the case of a pyrromethene 567 doped sample. The far field divergence was measured to be $1.4 \mathrm{mrad}$ and as the theoretical waist of the stable cavity we used for this 
experiment was $310 \mu \mathrm{m}$, the $\mathrm{M}^{2}$ value characterizing the spatial quality of the laser emission is 1.2 , close to the theoretical value of 1 for $\mathrm{TEM}_{00}$ beam indicating that the output beam is near diffraction limited.

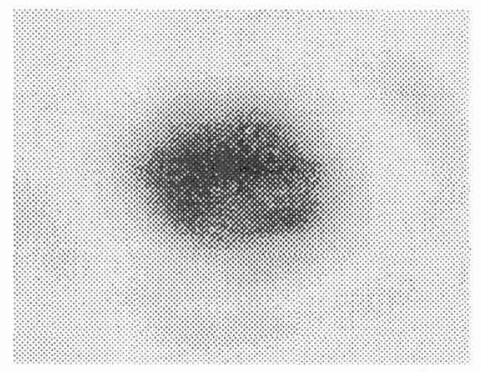

Figure 2. Spatial profile of the laser emission obtained with a pyrromethene 567 doped sample.

We also studied the evolution of the output energy as a function of the number of pump pulses. As the sample is used at the same point, the organic dye molecules slowly degrade and the effective concentration of the active species diminishes : therefore the laser action extinguishes after a certain number of operating pulses. We may characterize this behavior by the lifetime of the sample: it is the number of pump pulses the sample may support, at the same spot, while still giving way to emitted pulses of energy of more than a given fraction from the first emitted pulse. The lifetime is very strongly dependent on laser beam fluences in the sample and repetition rate, because of both the photodegradation and the thermodegradation processes. The longest lifetime recorded, in the energy range used in our optical set-up, was with a perylene red doped sample with a concentration of $5.5 \times 10^{-5} \mathrm{~mol} / \mathrm{l}$ pumping with $0.5 \mathrm{~mJ} / \mathrm{pulse}$ $\left(0.1 \mathrm{~J} / \mathrm{cm}^{2}\right.$ fluence) at $1 \mathrm{~Hz}$ repetition rate, the initial output energy being $0.1 \mathrm{~mJ}$, the slope efficiency obtained with that sample being $19 \%$. After 38,000 pulses, the output energy was still $62 \%$ of its initial value. This result is one order of magnitude better than those we had previously published using rhodamine doped geis [2]. Figure 3 presents the evolution of the output energy of our solid state dye laser as a function of the number of pump pulses. On this figure, a first increase in the output energy may be observed. This behavior can be explained by the fact that we have chosen to overconcentrate our sample. Using $1 \mathrm{~mJ}$ pump pulses at $1 \mathrm{~Hz}$, the lifetime were about 6,000 pulses with perylene orange, 5,000 pulses with pyrromethene $567\left(\mathrm{c}=5.10^{-4}\right.$ mol..$\left.^{-1}\right), 20,000$ pulses with perylene red, 2,250 pulses with 3,11-dimethoxy$5,6,8,9$-tetrahydro dibenzo xanthylium tetrafluoroborate and only a few hundred with rhodamine $6 \mathrm{G}$.

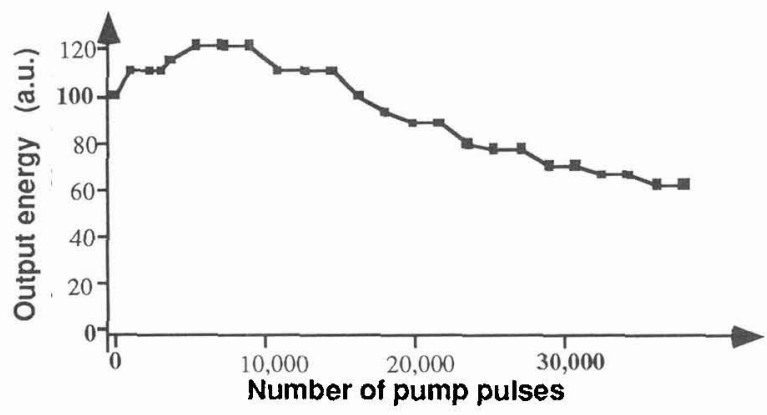

Figure 3 : Evolution of the output energy of the solid state dye laser as a function of the number of previous emitted pulses using a perylene red doped sample. 
To study the tunability of the cavity, the output coupler was replaced by a diffraction grating of 2,000 grooves $/ \mathrm{mm}$ used in a Littrow configuration, it may be characterized as follows: about $30 \%$ of reflection in the first order and $40 \%$ of transmission in the zero order around $600 \mathrm{~nm}$. The perylene and pyrromethene doped samples classically led to about $50 \mathrm{~nm}$ tuning ranges inside the 540-650 nm band [Fig. 4]. For example, the pyrromethene 567 doped sample allows to tune the cavity from 543 to $607 \mathrm{~nm}$, over $60 \mathrm{~nm}$, pumping at $0.2 \mathrm{~J} / \mathrm{cm}^{2}$ fluence level. With a 3,11-dimethoxy-5,6,8,9-tetrahydro dibenzo xanthylium tetrafluoroborate doped xerogel, the cavity was tunable over more than $75 \mathrm{~nm}$ from 555 to $631 \mathrm{~nm}$.

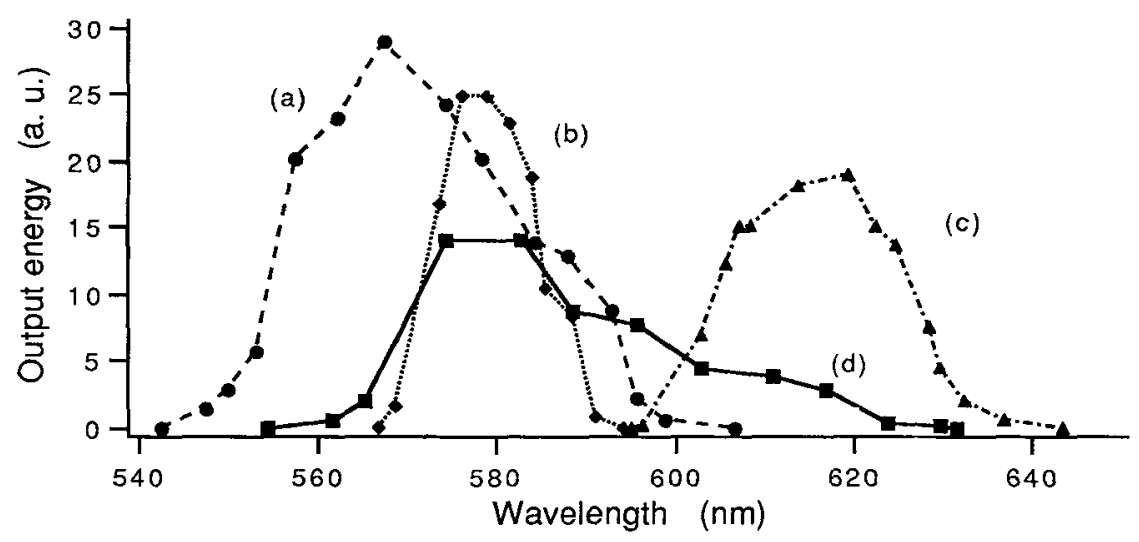

Figure 4: Tunability of the laser cavity when using the different dyes: (a) pyrromethene 567, (b) perylene orange. (c) perylene red and (d) 3,11-dimethoxy-5,6,8,9-tetrahydro dibenzo xanthylium tetrafluoroborate.

These results are, to our knowledge, the best achieved with doped xerogels, the lifetimes being significantly greater than those previously obtained by Altman et al. in the same energy range [3]. In the more general field of solid state dye lasers these performances are only overtaken by recent results of Allik et al. using a pyrromethene BF2 dye doped modified acrylic plastic rod [4]. All these results show however the progressive increases in terms of performances that happened in this field during the past years, and makes it now reasonable to forecast of practical applications for this new type of gain media. We believe that although the organic part of the matrix is essential for the dye to fluoresce and be photostable, the inorganic part of the xerogel may at the end reveal important to confer the necessary mechanical, thermal and optical uniform properties to allow these materials to become successful dye laser host.

Acknowledgements : We thank Prof. J. Kossanyi for providing us the broadband fluorescent xanthylium dye.

\section{References:}

[1] D. Doizi, J. Jaraudias, G. Salvetat, M.C. Gazeau, V. Wintgens, P. Valat and J. Kossanyi

"Laser performances of dibenzoxanthylium salts"

Optics Comm., 99, 207 (1993)

[2] M. Canva, P. Georges, A. Brun, D. Larrue and J. Zarzycki

"Impregnated $\mathrm{SiO}_{2}$ gels used as dye laser matrix hosts"

J. of Non-Crystalline Solids, 147 \& 148, 636-640, 1992.

[3] J.C. Altman, R.E. Stone, F. Nishida and B. Dunn

"Dye activated ORMOSIL'S for lasers and optical amplifiers"

SPIE Sol-Gel Optics II, 1758, 507-518, 1992.

[4] T. Allick, S. Chandra, R.E. Hermes, J.A. Hutchinson, M-L. Soong and J.H. Boyer "Efficient and robust solid-state dye laser"

Proccedings Advanced Solid State Dye Lasers, PD4/1-4, New Orleans, Feb 1-3 1993. 